Editor's Note: These short reviews of recent JNeurosci articles, written exclusively by students or postdoctoral fellows, summarize the important findings of the paper and provide additional insight and commentary. If the authors of the highlighted article have written a response to the Journal Club, the response can be found by viewing the Journal Club at www.jneurosci.org. For more information on the format, review process, and purpose of Journal Club articles, please see http://jneurosci.org/content/ preparing-manuscript\#journalclub.

\title{
Persistent "Sag" in Prefrontal Cortex Function following Adolescent Binge Drinking
}

\author{
(D)Max E. Joffe \\ Department of Pharmacology, Vanderbilt Center for Addiction Research, and Vanderbilt Center for Neuroscience Drug Discovery, Vanderbilt University, \\ Nashville Tennessee 37232 \\ Review of Salling et al.
}

Binge drinking, intermittent periods with high levels of alcohol consumption, is common among human adolescents. Alcohol exposure during adolescence can exert persistent effects on brain maturation and increase the risk of developing an alcohol use disorder (AUD) later in life. One key brain region involved with this long-term vulnerability is the prefrontal cortex (PFC). Substantial development of the PFC occurs during adolescence, allowing the PFC to moderate appetitive behaviors such as drinking. During this crucial developmental period, insults like drug or alcohol exposure can induce PFC impairments that extend into adulthood. Therefore, evaluating the changes that occur during adolescent binge drinking might improve our understanding of AUD etiology and aid efforts to develop novel treatments.

Its anatomical connections suggest that the PFC coordinates the sensation of external cues, the interpretation of moti-

\footnotetext{
Received July 11, 2018; revised Sept. 7, 2018; accepted Sept. 12, 2018.

Financial support was provided by a postdoctoral fellowship through the Pharmaceutical Research and Manufacturers of America Foundation. I thank Jeff and several members of the Conn laboratory for helpful and thought-provoking discussions.

The authors declare no competing financial interests.

Correspondence should be addressed to Dr. Max E. Joffe, Department of Pharmacology, Vanderbilt Center for Addiction Research, Vanderbilt Center for Neuroscience Drug Discovery, 12475E Medical Research Building IV, Nashville, TN 37232.E-mail: max.joffe@vanderbilt.edu.

https://doi.org/10.1523/JNEUROSCl.1755-18.2018

Copyright $\odot 2018$ the authors $\quad 0270-6474 / 18 / 389615-03 \$ 15.00 / 0$
}

vational state, and the execution of appetitive behaviors. Several physiological parameters modify the activity of layer 5 PFC pyramidal cells to regulate information outflow to other structures. These factors include excitatory synaptic drive, inhibitory transmission from interneurons, modulatory signaling from glia, and the membrane properties of the pyramidal cells themselves. Increasingly, longterm changes in membrane physiology (i.e., the plasticity of intrinsic excitability) are recognized to contribute to persistent behavioral adaptations following exposure to drugs or alcohol (Kourrich et al., 2015; Harrison et al., 2017). While several studies have demonstrated that chronic ethanol exposure reorganizes synaptic transmission in the deep layers of the PFC (Kroener et al., 2012; Klenowski et al., 2016; Centanni et al., 2017; TranthamDavidson et al., 2017), the effects on intrinsic excitability remain less well understood. In a recent article in The Journal of Neuroscience, Salling et al. (2018) address this gap by assessing how adolescent binge drinking alters membrane physiology in the adult mouse PFC.

Salling et al. (2018) gave mice voluntary access to ethanol during the critical adolescent developmental window [postnatal day 28 (P28) to P60], then assessed PFC-dependent behaviors in adulthood (P65-P95). Mice were given two drinking bottles in their home cage and received access to $15 \%$ ethanol every other day. During the first five sessions, mice escalated their voluntary drinking, peaking at $\sim 18 \mathrm{~g} / \mathrm{kg} / \mathrm{d}$. Importantly, the mean blood alcohol content (BAC) reached nearly 90 $\mathrm{mg} / \mathrm{dl}$, surpassing the commonly defined threshold for binge drinking $(80 \mathrm{mg} / \mathrm{dl})$.

After at least $3 \mathrm{~d}$ of withdrawal, behavioral experiments were performed to assess the long-term consequences of adolescent intermittent ethanol consumption. Despite commonly observed affective disturbances during ethanol withdrawal (Holleran and Winder, 2017), the authors found no evidence of anxiety-like behavior. Mice were then trained to perform a maze-based nonmatch to sample task; performance on such tasks depends on PFC function (Kellendonk et al., 2006; Moore et al., 2012). Salling et al. (2018) had mice explore one arm of a T-shaped maze during a sample period, then, in the choice phase, reinforced mice if they turned toward the opposite arm. The binge-drinking group required more training sessions, on average, to reach $80 \%$ accuracy on the task, suggesting a mild deficit in rule learning or working memory. To specifically examine working memory, a delay period (5-180 s) was inserted between the sample and choice phases. The ethanolexposed mice displayed lower accuracy during this task, particularly following long delays that require relatively high cognitive demand. These findings suggest that adolescent binge drinking can induce working 
memory impairments that persist into adulthood.

Next, the authors assessed the longterm impact of adolescent intermittent ethanol consumption on adult drinking behavior. To the authors' surprise, no effects on total ethanol consumed or BAC attained were observed; however, adult mice that had consumed ethanol intermittently during adolescence drank more during the first $5 \mathrm{~min}$ of the sessions than controls did. Similar "front-loading" drinking behaviors have been observed in humans with increased AUD vulnerability (Gowin et al., 2017), suggesting that long-term disease-relevant behavioral changes are present in this mouse model.

Because the PFC is a key brain region supporting working memory and the moderation of drinking behaviors, Salling et al. (2018) examined whether intermittent ethanol consumption affects intrinsic plasticity in layer 5 pyramidal cells, the primary output neurons of the rodent PFC. Membrane physiology was assessed using whole-cell patch-clamp recordings. The resting membrane potential was more hyperpolarized in pyramidal cells in the binge-drinking group compared with controls immediately after ethanol exposure, and this change persisted for up to $30 \mathrm{~d}$ of abstinence. During hyperpolarizing current steps, PFC pyramidal cells display a depolarizing voltage rebound, or "sag," which is typically mediated by hyperpolarization-activated cyclic nucleotide-gated cation (HCN) channels (Thuault et al., 2013; Shah, 2014). Because this sag limits the hyperpolarization of the resting membrane potential, loss of this current might explain the hyperpolarized resting potential after binge drinking. Consistent with this hypothesis, the sag ratio (the difference between the peak and steady-state voltages in response to hyperpolarizing current) was lower in the binge-drinking group than in controls. Moreover, an HCN channel inhibitor mimicked the ethanol-induced membrane hyperpolarization and decrease in sag ratio, and abrogated differences in both measurements between the control and binge-drinking groups. Finally, Salling et al. (2018) corroborated these findings using immunohistochemistry. While no difference in total Hcnl expression was observed, adolescent binge drinking was associated with decreased expression of Trip8b, a subunit required for trafficking Hcn 1 to the plasma membrane in pyramidal cells (Shah, 2014). Together, these convergent findings suggest that adoles- cent binge drinking generated a long-term impairment in PFC HCN channel function, concomitant with persistent changes in working memory and drinking behavior.

Collectively, the findings by Salling et al. (2018) provide insight about why AUD patients might have deficits in working memory (Abernathy et al., 2010), a process subserved by reciprocal connections between the PFC and mediodorsal thalamus (MDT; Bolkan et al., 2017). Output from the PFC to the MDT is thought to be particularly important during the choice phase of working memory tasks, when actions are selected based on recent experiences. One possible mechanism underlying the drinking-induced working memory deficit is that membrane hyperpolarization decreases the activity of MDT-projecting pyramidal cells. Neurons that rest at hyperpolarized potentials require more stimulation to fire action potentials and transmit information to downstream structures. Therefore, the reduced function of $\mathrm{HCN}$ channels and resulting membrane hyperpolarization could decrease the likelihood of PFC-MDT pyramidal cells to reach threshold and impair the conversion of a shortterm memory into an appropriate action.

An alternative possibility is that alcoholinduced loss of HCN channels increases the activity of pyramidal cells. In addition to modulating membrane potential, $\mathrm{HCN}$ channels regulate the integration of synaptic inputs to pyramidal cells. $\mathrm{HCN}$ channels allow cations to traverse the membrane when pyramidal cells are at resting potentials. Due to this property, HCN channels decrease the membrane resistance and ensure that relatively large currents are required to depolarize the surface membrane in select locations, such as spine necks (Wang et al., 2007). Dendritic HCN channels thereby gate the flow of information toward the soma, and decreased Hcn 1 function can enhance synaptic drive and subsequent pyramidal cell activity (Huang et al., 2009). Moreover, neurons that project to the MDT seem particularly susceptible to this $\mathrm{HCN}$ mediated disinhibition (Ying et al., 2012). Based on this, decreased dendritic HCN channel function resulting from adolescent binge drinking might induce an overactive or asynchronous PFC-MDT circuit and disrupt working memory performance through premature, perseverative, or inappropriate action selection.

At face value, the loss of HCN channel function seems to induce opposing expected changes to pyramidal cells: decreased spiking through somatic hyperpolarization versus increased synaptic activity via disinhibition.
While both outcomes could occur in a single cell, it is likely that one mechanism would induce a greater impact on neuron activity in vivo, and future studies should shed light on those outcomes. Additionally, these changes to somatic and dendritic $\mathrm{HCN}$ channel functions could occur simultaneously in separable pyramidal cell subpopulations. For example, MDTprojecting pyramidal cells might display distinct changes from neighboring neurons that project to the striatum. This raises the possibility that decreased dendritic HCN channel function induces the hyperactivity of MDT-projecting neurons, while somatic hyperpolarization attenuates PFC output to the striatum. This hypothesis has important ramifications for the different behaviors affected by adolescent binge drinking. The working memory deficit is likely subserved by the dysregulation of MDT-projecting neurons, whereas an impairment in top-down control of the striatum might mediate the frontloading drinking phenotype. Future studies should elucidate how HCN channels modulate specific PFC subpopulations to shed light on these potential mechanisms.

Genetic deletion of Hcn 1 in the PFC can disrupt working memory (Thuault et al., 2013; but see also Wang et al., 2007). While decreased surface expression of $H c n 1$ provides a potential mechanism for diminished HCN channel function in the present studies, a second nonexclusive explanation is that binge drinking disrupts second messengers or signaling partners that interact with $\mathrm{HCN}$ channels. $\mathrm{HCN}$ channel function is gated by the intracellular pool of cAMP. In the PFC, dopamine and noradrenaline receptors regulate local cAMP concentrations and are also known to modulate HCN channel function and working memory (Wang et al., 2007). These findings raise the possibility that chronic alterations in PFC monoamine signaling might underlie the generation or expression of pathophysiological changes induced by adolescent binge drinking. Consistent with that hypothesis, Trantham-Davidson et al. (2017) found that several functions of $\mathrm{G}_{\mathrm{s} / \mathrm{olf}}$-coupled $\mathrm{D}_{1}$ dopamine receptors in the adult $\mathrm{PFC}$ were abolished after adolescent ethanol exposure. Thus, an impairment in $\mathrm{D}_{1}$ stimulated CAMP production might contribute to long-lasting deficits in $\mathrm{HCN}$ function and working memory. Other receptors that might be involved in PFC pathophysiology following adolescent drinking include the $\alpha_{2 \mathrm{~A}}$ adrenoreceptor (Wang et al., 2007) and $\mathrm{mGlu}_{3}$ metabotropic glutamate receptor (Jin et 
al., 2017). These $\mathrm{G}_{\mathrm{i} / \mathrm{o}}$-coupled receptors are thought to be expressed in close proximity to PFC HCN channels and have been implicated in both working memory and ethanol seeking (Joffe et al., 2018). Based on these links, manipulations that potentiate $\mathrm{D}_{1}$ or inhibit $\alpha_{2 \mathrm{~A}}$ or $\mathrm{mGlu}_{3}$ might be explored as means to mitigate deficits in HCN channel function, working memory, and/or ethanol seeking observed following adolescent binge drinking. In conclusion, Salling et al. (2018) make several advances that enhance our understanding of how adolescent binge drinking confers long-term PFC deficits. These findings highlight the importance of studying intrinsic plasticity to fully understand experience-induced changes in PFC function.

\section{References}

Abernathy K, Chandler LJ, Woodward JJ (2010) Alcohol and the prefrontal cortex. Int Rev Neurobiol 91:289-320. CrossRef Medline

Bolkan SS, Stujenske JM, Parnaudeau S, Spellman TJ, Rauffenbart C, Abbas AI, Harris AZ, Gordon JA, Kellendonk C (2017) Thalamic projections sustain prefrontal activity during working memory maintenance. Nat Neurosci 20:987-996. CrossRef Medline

Centanni SW, Burnett EJ, Trantham-Davidson H, Chandler LJ (2017) Loss of delta-GABAA receptor-mediated tonic currents in the adult prelimbic cortex following adolescent alcohol exposure. Addict Biol 22:616-628. CrossRef Medline

Gowin JL, Sloan ME, Stangl BL, Vatsalya V, Ramchandani VA (2017) Vulnerability for alcohol use disorder and rate of alcohol consumption. Am J Psychiatry 174:1094-1101. CrossRef Medline

Harrison NL, Skelly MJ, Grosserode EK, Lowes DC, Zeric T, Phister S, Salling MC (2017) Ef- fects of acute alcohol on excitability in the CNS. Neuropharmacology 122:36-45. CrossRef Medline

Holleran KM, Winder DG (2017) Preclinical voluntary drinking models for alcohol abstinence-induced affective disturbances in mice. Genes Brain Behav 16:8-14. CrossRef Medline

Huang Z, Walker MC, Shah MM (2009) Loss of dendritic HCN1 subunits enhances cortical excitability and epileptogenesis. J Neurosci 29: 10979-10988. CrossRef Medline

Jin LE, Wang M, Yang ST, Yang Y, Galvin VC, Lightbourne TC, Ottenheimer D, Zhong Q, Stein J, Raja A, Paspalas CD, Arnsten AFT (2017) mGluR2/3 mechanisms in primate dorsolateral prefrontal cortex: evidence for both presynaptic and postsynaptic actions. Mol Psychiatry 22:1615-1625. CrossRef Medline

Joffe ME, Centanni SW, Jaramillo AA, Winder DG, Conn PJ (2018) Metabotropic glutamate receptors in alcohol use disorder: physiology, plasticity, and promising pharmacotherapies. ACS Chem Neurosci. Advance online publication. Retrieved September 18, 2018. doi:10. 1021/acschemneuro.8b00200. CrossRef Medline

Kellendonk C, Simpson EH, Polan HJ, Malleret G, Vronskaya S, Winiger V, Moore H, Kandel ER (2006) Transient and selective overexpression of dopamine D2 receptors in the striatum causes persistent abnormalities in prefrontal cortex functioning. Neuron 49:603-615. CrossRef Medline

Klenowski PM, Fogarty MJ, Shariff M, Belmer A, Bellingham MC, Bartlett SE (2016) Increased synaptic excitation and abnormal dendritic structure of prefrontal cortex layer $\mathrm{V}$ pyramidal neurons following prolonged binge-like consumption of ethanol. eNeuro 3:ENEURO.0248-16.2016. CrossRef Medline

Kourrich S, Calu DJ, Bonci A (2015) Intrinsic plasticity: an emerging player in addiction. Nat Rev Neurosci 16:173-184. CrossRef Medline

Kroener S, Mulholland PJ, New NN, Gass JT, Becker HC, Chandler LJ (2012) Chronic alcohol exposure alters behavioral and synaptic plasticity of the rodent prefrontal cortex. PLoS One 7:e37541. CrossRef Medline

Moore TL, Schettler SP, Killiany RJ, Rosene DL, Moss MB (2012) Impairment in delayed nonmatching to sample following lesions of dorsal prefrontal cortex. Behav Neurosci 126: 772-780. CrossRef Medline

Salling MC, Skelly MJ, Avegno E, Regan S, Zeric T, Nichols E, Harrison NL (2018) Alcohol consumption during adolescence in a mouse model of binge drinking alters the intrinsic excitability and function of the prefrontal cortex through a reduction in the hyperpolarization-activated cation current. J Neurosci 38:6207-6222. CrossRef Medline

Shah MM (2014) Cortical HCN channels: function, trafficking and plasticity. J Physiol 592: 2711-2719. CrossRef Medline

Thuault SJ, Malleret G, Constantinople CM, Nicholls R, Chen I, Zhu J, Panteleyev A, Vronskaya S, Nolan MF, Bruno R, Siegelbaum SA, Kandel ER (2013) Prefrontal cortex HCN1 channels enable intrinsic persistent neural firing and executive memory function. J Neurosci 33:13583-13599. CrossRef Medline

Trantham-Davidson H, Centanni SW, Garr SC, New NN, Mulholland PJ, Gass JT, Glover EJ, Floresco SB, Crews FT, Krishnan HR, Pandey SC, Chandler LJ (2017) Binge-like alcohol exposure during adolescence disrupts dopaminergic neurotransmission in the adult prelimbic cortex. Neuropsychopharmacology 42: 1024-1036. CrossRef Medline

Wang M, Ramos BP, Paspalas CD, Shu Y, Simen A, Duque A, Vijayraghavan S, Brennan A, Dudley A, Nou E, Mazer JA, McCormick DA, Arnsten AF (2007) Alpha2A-adrenoceptors strengthen working memory networks by inhibiting cAMP-HCN channel signaling in prefrontal cortex. Cell 129:397-410. CrossRef Medline

Ying SW, Kanda VA, Hu Z, Purtell K, King EC, Abbott GW, Goldstein PA (2012) Targeted deletion of Kcne2 impairs HCN channel function in mouse thalamocortical circuits. PLoS One 7:e42756. CrossRef Medline 